\title{
A continuous quality improvement intervention to improve the effectiveness of community health workers providing care to mothers and children: a cluster randomised controlled trial in South Africa
}

\author{
Christiane Horwood ${ }^{1 *}$ D, Lisa Butler ${ }^{2}$, Pierre Barker ${ }^{3,4}$, Sifiso Phakathi ${ }^{1}$, Lyn Haskins', Merridy Grant ${ }^{1}$,
} Ntokozo Mntambo ${ }^{1}$ and Nigel Rollins ${ }^{5}$

\begin{abstract}
Background: Community health workers (CHWs) play key roles in delivering health programmes in many countries worldwide. CHW programmes can improve coverage of maternal and child health services for the most disadvantaged and remote communities, leading to substantial benefits for mothers and children. However, there is limited evidence of effective mentoring and supervision approaches for CHWs.

Methods: This is a cluster randomised controlled trial to investigate the effectiveness of a continuous quality improvement (CQI) intervention amongst CHWs providing home-based education and support to pregnant women and mothers. Thirty CHW supervisors were randomly allocated to intervention $(n=15)$ and control $(n=15)$ arms. Four CHWs were randomly selected from those routinely supported by each supervisor ( $n=60$ per arm). In the intervention arm, these four CHWs and their supervisor formed a quality improvement team. Intervention CHWs received a 2-week training in WHO Community Case Management followed by CQI mentoring for 12 months (preceded by 3 months lead-in to establish Ql processes). Baseline and follow-up surveys were conducted with mothers of infants $<12$ months old living in households served by participating CHWs.
\end{abstract}

Results: Interviews were conducted with 736 and 606 mothers at baseline and follow-up respectively; sociodemographic characteristics were similar in both study arms and at each time point.

At follow-up, compared to mothers served by control CHWs, mothers served by intervention CHWs were more likely to have received a CHW visit during pregnancy $(75.7$ vs $29.0 \%, p<0.0001)$ and the postnatal period $(72.6$ vs $30.3 \%, p<0.0001$ ). Intervention mothers had higher maternal and child health knowledge scores (49 vs 43\%, $p=0$. 02 ) and reported higher exclusive breastfeeding rates to 6 weeks (76.7 vs $65.1 \%, p=0.02$ ). HIV-positive mothers served by intervention CHWs were more likely to have disclosed their HIV status to the CHW (78.7 vs 50.0\%, $p=0$. 007). Uptake of facility-based interventions were not significantly different.

Conclusions: Improved training and CQI-based mentoring of CHWs can improve quantity and quality of CHWmother interactions at household level, leading to improvements in mothers' knowledge and infant feeding practices.

\footnotetext{
* Correspondence: horwoodc@ukzn.ac.za

${ }^{1}$ Centre for Rural Health, University of KwaZulu-Natal, Durban, KwaZulu-Natal,

South Africa

Full list of author information is available at the end of the article
} 
(Continued from previous page)

Trial registration: ClinicalTrials.Gov NCT01774136

Keywords: Community health worker, Quality improvement, Breastfeeding, South Africa, Maternal health, Child health, HIV

\section{Background}

Community health workers (CHWs) are generally defined as community members chosen by their community to support or provide health interventions at household level; they are linked to the health system, but have shorter training than professional health workers [1]. Deployment of CHWs can address barriers to preventive and curative care, increasing coverage of key interventions including maternal and child health services, and improve continuity of care during pregnancy and the postnatal period [2]. Together, these can accrue substantial health benefits for communities including mothers and children [3].

In South Africa, where HIV prevalence amongst pregnant women varies between 16.9 and $37.4 \%$ across provinces [4], maternal and child mortality remain higher than expected despite evidence-based packages of care being available in primary health care (PHC) facilities [5]. To improve survival, coverage of key interventions must increase, particularly early antenatal care (ANC) attendance (before 22 weeks), postnatal care and infant feeding support, prevention of mother-to-child HIV transmission (PMTCT) interventions and early access to antiretroviral therapy (ART) for mothers living with HIV and their infants.

However, improvements in facility-based care for pregnant women, mothers and children may have limited impact. In South Africa, over half of child deaths occur outside of the health facility [6] largely due to a failure to recognise serious illness amongst children in the home, so that children present late to health facilities. CHW-based interventions may bridge this gap and, in some settings, have substantially reduced maternal and neonatal mortality [7-10]. Elsewhere, however, CHW interventions that improved knowledge and care practices amongst mothers had no effect on maternal and child health outcomes [11]. The implementation and outcome of CHW programmes is dependent not only on appropriate training but also on support and effective supervision that is coordinated with PHC services [2].

In South Africa, most CHWs are recruited and employed by the Department of Health and receive a small stipend. CHWs fulfil a variety of roles in the community including home-based care, adherence support for antiretroviral and TB treatment as well as provision of maternal and child health $(\mathrm{MCH})$ services. Their role in provision of $\mathrm{MCH}$ services in households includes counselling about early ANC attendance, identification of danger signs in newborns and support for breastfeeding and is clearly described in the Department of Health policy for community-based maternal, child and newborn care [12].

In this study, we implemented the WHO Community Case Management (CCM) training [13], combined with ongoing mentoring using a continuous quality improvement (CQI) approach [14], to improve and maintain skills of CHWs caring for mothers and children in the community. CCM is based on treatment algorithms developed for Integrated Management of Childhood Illness (IMCI) and broadens access to care by equipping CHWs with skills to support pregnant women and assess and manage sick infants and children in the household [15]. We adapted CCM materials to include interventions to support uptake and delivery of PMTCT and ART services.

CQI is a simple, low-tech approach to the management and supervision of health programmes which has been successfully used to improve PMTCT uptake at facility level in South Africa [16, 17]. The CQI method guides practitioners to better performance by using locally generated data to provide feedback on practices and knowledge. Once gaps in performance are shown, health workers generate, develop and test local solutions and track change in performance to achieve improvement $[14,18]$.

Here, we report the number of $\mathrm{CHW}$ visits and changes in maternal knowledge, household child care practices, care-seeking behaviour and uptake of facilitybased maternal and child health interventions by mothers residing in households served by CHWs provided with additional training and supervised using a CQI mentoring approach.

\section{Methods}

\section{Study design}

This is a cluster randomised controlled trial in which 30 CHW supervisors in a high HIV prevalence rural community in South Africa were randomly allocated to intervention $(n=15)$ and control $(n=15)$ arms. From the CHWs routinely managed by each supervisor, four were randomly selected ( $n=60$ per study arm). CHWs in the intervention arm received training in WHO HIVadapted CCM, formed quality improvement teams (comprising the $\mathrm{CHW}$ supervisor and four selected $\mathrm{CHWs}$ ) 
and participated in bi-monthly mentoring using CQI methods for 15 months including a 3-month lead-in period. Participants received no monetary or other incentives to participate.

To assess the effect of the intervention on maternal health behaviour, knowledge and infant feeding practices, household surveys were conducted amongst independent samples of mothers of infants aged $<12$ months old residing in households served by participating CHWs. Surveys were conducted at baseline, prior to implementation of CCM training and CQI mentoring and at follow-up, 15 months following initiation of the intervention.

An independent assessment team conducted the two surveys using a structured questionnaire in the local language (isiZulu). Paper questionnaires were used at baseline, and a tablet-based data collection system was used for the follow-up survey.

\section{Study setting}

The study was conducted in Ugu Health District, KwaZulu-Natal (KZN), South Africa. This district has a population of approximately 700000 people, predominantly living in rural areas. There are 47 fixed PHC clinics, 14 mobile clinics, three district hospitals and one regional hospital located in the district. CHW supervisors are experienced CHWs selected by the local health authorities, have a minimum grade 12 education and three or more years of experience as a CHW. CHWs provide support to households within geographically distinct catchment areas and visit pregnant women and new mothers regularly during pregnancy and postdelivery. At the time of the study, there were $32 \mathrm{CHW}$ supervisors and $956 \mathrm{CHWs}$ providing services to communities in the district. On average, each participating supervisor supervised $26 \mathrm{CHWs}$ (range 7-59).

\section{Study participants: CHWs and mothers}

All CHW supervisors working in the district and all CHWs with a minimum grade 10 education were eligible for randomisation into the study. Supervisors and CHWs identified through randomisation were subsequently invited to participate.

Mothers were recruited into the surveys if they were aged 18 years or more, had an infant aged less than 12 months of age and were living in a household served by a participating $\mathrm{CHW}$. Mothers were not eligible if they had resided in another community in the 12 months prior to the study. All eligible mothers were invited to participate.

\section{CHW training}

All CHWs had received routine 10-day KZN Department of Health training on community-based care of women and infants prior to study implementation. In the intervention arm, $\mathrm{CHW}$ improvement teams received two additional weeks of training on community care of pregnant women and newborns based on WHO CCM materials [19] adapted to include relevant aspects of HIV care. Training included guidelines on antenatal and postnatal visits, with information on HIV and PMTCT, as well as identification of signs of illness in newborn infants and children. Training was supported by detailed materials, conducted in the local language (isiZulu) and included both theoretical and clinical components. Training was conducted with three groups of 25 participants between May and August 2012.

\section{CQI intervention}

The 12-month CQI mentoring intervention was preceded by a 3-month lead-in phase to establish mentoring meetings and processes and was conducted between $\mathrm{Au}$ gust 2012 and November 2013. CHWs routinely documented and summarised a limited set of data for women they visited, including gestational age at first booking (from ANC cards), if women had ever tested for HIV (without documenting test results), coverage of PMTCT interventions, delivery site (home or facility) and early infant feeding practices. CHW improvement teams received bi-monthly mentoring from experienced quality mentors based at the University of KZN and employed by the project, using a CQI approach. During mentoring meetings, teams reviewed data elements collected by CHWs to identify gaps and together design tests of ideas for how challenges could be resolved. Quarterly learning sessions were convened at which $\mathrm{CHW}$ improvement teams presented their progress to provide opportunities for peer learning across CHW groups. This intervention is described further elsewhere [20].

\section{Measurements at baseline and follow-up Care-seeking}

Mothers were asked if she had needed to go to the clinic in the past 6 months, either for herself or for her child, but had not gone for any reason.

\section{CHW visits}

Mothers were asked if and how often the CHW had visited during pregnancy and after delivery and if the $\mathrm{CHW}$ had provided information about key antenatal and postnatal health topics.

\section{Maternal, neonatal and child health knowledge}

Knowledge was assessed using four questions. A total knowledge score for each participant was calculated; see Table 1 for details on scoring. 
Table 1 Scoring system for maternal knowledge

\begin{tabular}{|c|c|c|}
\hline Question & Correct answer(s) and coding & $\operatorname{Max}$ \\
\hline Q1. When in your pregnancy should you go for your first antenatal visit? & $\begin{array}{l}\text { Correct answer: As soon as you have missed your } \\
\text { period or as soon as you suspect you are pregnant or similar } \\
\text { Score }=1\end{array}$ & 1 \\
\hline Q2. How many antenatal visits should you go for during your pregnancy? & $\begin{array}{l}\text { Correct answer: four or more } \\
\text { Score }=1\end{array}$ & 1 \\
\hline Q3. What are danger signs you should look out for during your pregnancy? & $\begin{array}{l}\text { Correct answers: } \\
\text { Vaginal bleeding } \\
\text { Shortness of breath } \\
\text { Severe abdominal pain } \\
\text { Fits } \\
\text { Headaches } \\
\text { Swelling of feet and face } \\
\text { Decreased movements of the baby } \\
\text { Score = no. of correctly mentioned }\end{array}$ & 7 \\
\hline $\begin{array}{l}\text { Q4. What are the danger signs that would make you take a newborn baby } \\
\text { urgently to the clinic? }\end{array}$ & $\begin{array}{l}\text { Correct answers: } \\
\text { Not able to feed well } \\
\text { Had a convulsion or fit } \\
\text { Shortness of breath } \\
\text { High temperature } \\
\text { Low temperature } \\
\text { Yellow skin and eyes } \\
\text { Only moves when stimulated } \\
\text { Pus draining from umbilicus } \\
\text { Pus draining from eyes } \\
\text { Score = no. of correctly mentioned }\end{array}$ & 8 \\
\hline Total knowledge score & Mean score of Q1 + Q2 + Q3 + Q4 & 17 \\
\hline
\end{tabular}

\section{Infant feeding practices}

Mothers of infants under 6 months old were asked if they had ever breastfed their infant, if they were currently breastfeeding and, if the infant was $>6$ weeks old, how they fed their infant during the first 6 weeks of life.

\section{Statistical analysis}

Demographic characteristics in baseline and follow-up study samples in the intervention and control groups were summarised by percentages, means and standard deviations. Outcomes were compared between intervention and control groups using intention to treat analysis. Outcomes were compared at each time point and changes in each group compared between time points. These comparisons were made first without adjustment, followed by repeated-measures linear or logistic regression, as appropriate, for continuous or dichotomous measures, respectively, with random intercepts for supervisors and CHWs within the experimental group. The regression models used change between time points as the dependent variable. To account for within-subject correlation of measurements over time, we used the SAS MIXED procedure for numeric outcomes [21] and SAS GENMOD procedure to implement the generalised estimating equation (GEE) approach for binary outcomes $[22,23]$. Results were expressed as odds ratios (OR) with $95 \% \mathrm{CI}$. The $p$ values were two-sided and statistical significance was defined at the $5 \%$ level. All analyses were conducted with type I error set at 0.05 for each pairing of dependent and independent variables. The SAS statistical software package 9.2 was used for all computations.

\section{Ethics}

Written informed consent was obtained from all participating CHWs, supervisors and mothers. Ethical approval was obtained from the Biomedical Ethics Review Committee at the University of KwaZulu-Natal (BGC077/11), World Health Organization and the University of California, San Francisco (12-08526). Permission to undertake the study was obtained from the KZN Department of Health.

\section{Results}

The baseline survey was conducted between April and August 2012 and the follow-up survey between November 2013 and March 2014. Participating CHWs provided a list of households served at each time point. One intervention CHW dropped out due to language difficulties and one control CHW died during the course of the study; however, data was collected both at baseline and follow-up in the households served by these participants. Each CHW served an average of 62 households (range 28-155). Participant enrolment and allocation are shown in Fig. 1.

Social and demographic characteristics of interviewed mothers are described in Table 2. These were similar in the intervention and control arms at both survey time points. 


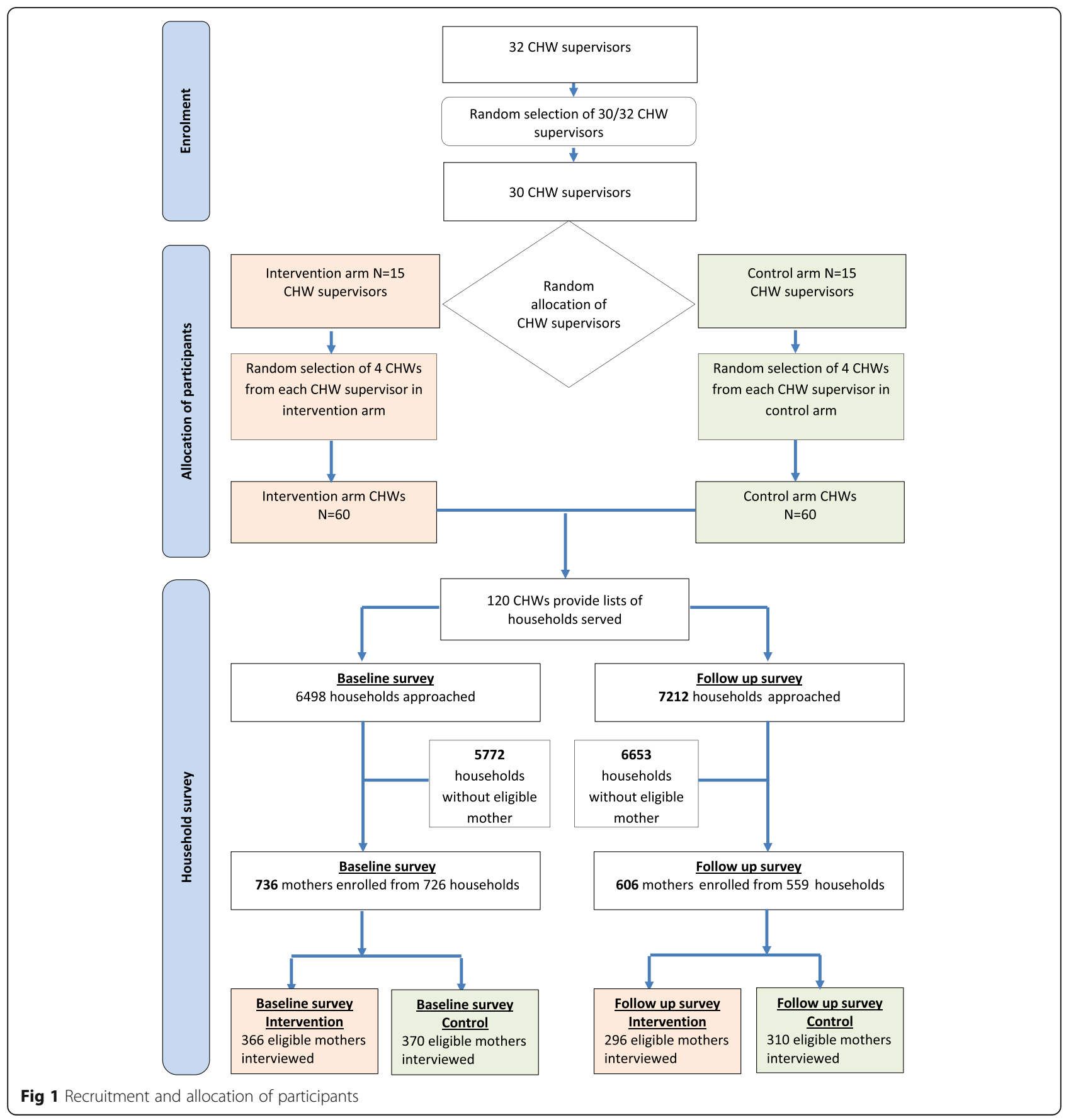

\section{CHW visits}

The frequency of and activities completed during CHW visits amongst pregnant women are shown in Table 3. Improvements in mother-reported provision of health information were observed amongst intervention CHWs compared to control CHWs. Changes differed significantly between groups (time $\times$ treatment interaction) with respect to provision of information about early ANC attendance ( $p$ $<0.0001)$, danger signs in pregnancy $(p<0.0001)$, importance of going to clinic for postnatal care $(p<0.0001)$, infant feeding $(p<0.0001)$ and danger signs in newborn babies $(p<0.0001)$. Provision of breastfeeding assistance was higher in the intervention group $(p<0.001)$.

Among only those mothers who reported receiving a visit from a $\mathrm{CHW}$ at follow-up, mothers in the intervention group were more likely than control mothers to have received key health information during these visits: $70 / 90(77.8 \%)$ vs $214 / 224(95.5 \%, p=0.0003)$ for danger signs in pregnancy, $74 / 90(82.2 \%)$ vs $211 / 224$ (94.2\%, $p$ $=0.01)$ for feeding advice, 65/94 (69.2\%) vs $175 / 215$ 


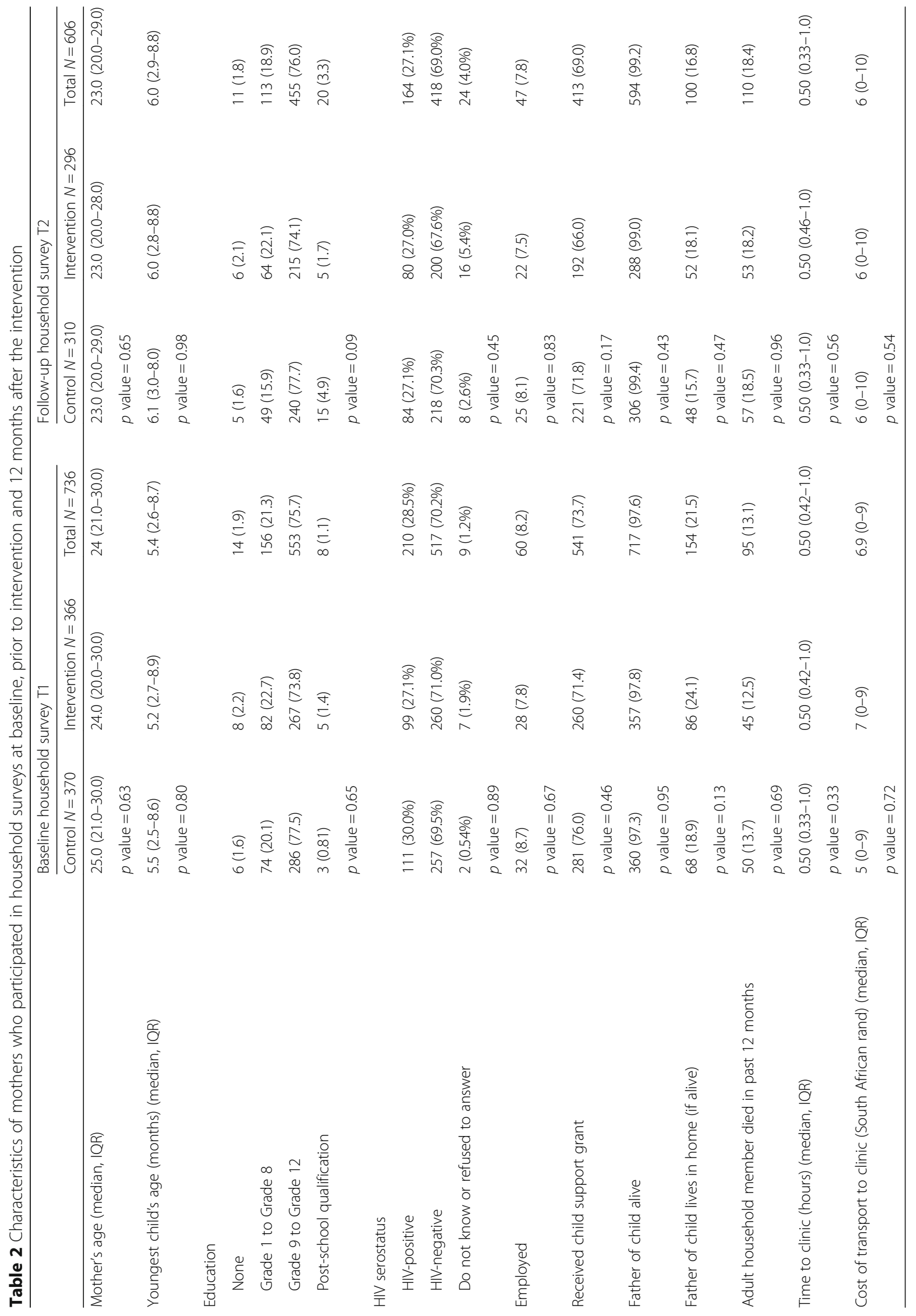




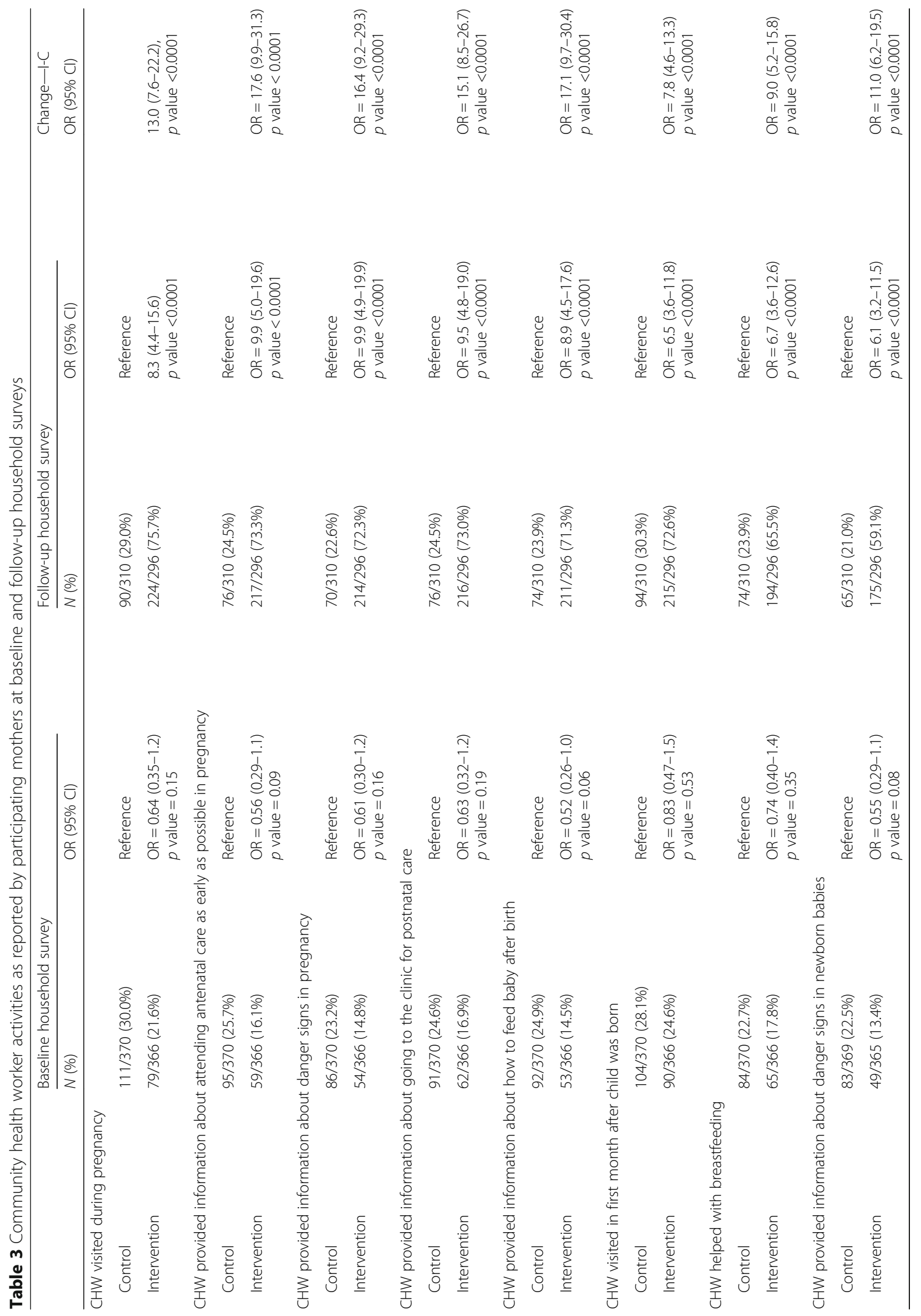


(81.4\%, $p=0.01)$ for danger signs in newborns and 74/94 $(78.7 \%)$ vs $194 / 215(90.2 \%, p=0.01)$ received assistance with breastfeeding.

Amongst mothers who self-reported being HIVpositive and being visited by a CHW, 24/43 (55.8\%) mothers in the control group and 17/30 (56.7\%) mothers in the intervention group reported having disclosed their HIV-positive status to their CHW $(p=0.94)$ at baseline. However, at follow-up, significantly more HIV-positive mothers in the intervention group reported having disclosed to their $\mathrm{CHW}$ than mothers in the control group (59/72 [81.9\%] vs 23/46 [50.0\%] $p=0.007)$.

\section{Care-seeking}

Self-reported care-seeking practices over the preceding 6 months amongst participating mothers at baseline and follow-up are shown in Table 4. At follow-up, significantly fewer intervention mothers reported failing to seeking treatment when needed for themselves or for their child(ren). Time and costs to attend the clinic were similar in both groups at both time points (Table 2).

\section{Infant feeding}

Infant feeding practices amongst participating mothers at baseline and follow-up are shown in Table 5. At follow-up, a significantly greater proportion of mothers in the intervention group reported having exclusively breastfed their infant for 6 weeks $(p=0.02)$. Further, the changes from baseline to follow-up differed between groups $(p=0.001$ for time $\times$ treatment interaction).

\section{Knowledge about maternal, neonatal and child health}

Knowledge was similar in both intervention and control groups at baseline (mean score $48 \%$ in both intervention and control groups, $p=0.85$ ). At follow-up, there was a statistically significant difference in mean knowledge scores between intervention and control participants (mean scores 49 vs $43 \%, p=0.008)$. When the change in knowledge was examined, there was a statistically significant difference between the two groups $(p=0.002$ for time $\times$ treatment interaction).

\section{Coverage of facility-based services}

Attendance at clinics was high for both groups at all measured times in the study with no significant differences observed. ANC attendance at baseline was high in intervention and follow-up groups (98.6 vs $98.1 \%, p$ $=0.58$ ) and was similar at follow-up (95.8 vs 98.4\%, $p=$ 0.09). Attendance for postnatal care within 1 week of delivery was high amongst both intervention and control groups at baseline (87.1 vs $82.8 \%, p=0.24)$ and at follow-up (91.7 vs $88.3 \%, p=0.19$ ), with no differences between groups or at different survey time points. Amongst HIV-positive women at both survey time points, coverage of HIV testing and care and treatment services were high. The proportion of HIV positive mothers currently on ART was high in both intervention and control groups at baseline (87.8 vs $90.4 \%, p=$ 0.99 ) and was $98.4 \%$ for both intervention and control groups at follow-up $(p=0.98)$.

\section{Discussion}

We found that providing WHO adapted CCM training to CHWs supported by a CQI-based model of mentoring substantially increased the number of antenatal and postnatal household visits by CHWs and the proportion of mothers who were able to recall key health promotion messages. This was associated with improved infant feeding practices and care-seeking behaviours of mothers.

At follow-up, fewer mothers served by intervention CHWs reported failing to seek care if they or their infants were unwell. This may have been due to improved knowledge of mothers regarding danger signs amongst newborns and self-initiated attendance or because of direct prompting by CHWs who were visiting households more frequently.

Mothers served by intervention CHWs were more likely to disclose their HIV status to the CHW. This

Table 4 Care-seeking practices amongst participating mothers at baseline and follow-up household surveys household survey T1 and $\mathrm{T} 2$

\begin{tabular}{|c|c|c|c|c|c|}
\hline & \multicolumn{2}{|c|}{ Baseline household survey } & \multicolumn{2}{|c|}{ Follow-up household survey } & \multirow{2}{*}{$\begin{array}{l}\text { Change-I-C, } \\
\text { T1-T2 } \\
\text { OR }(95 \% \mathrm{Cl})\end{array}$} \\
\hline & $\overline{N(\%)}$ & OR $(95 \% \mathrm{Cl})$ & $N(\%)$ & OR $(95 \% \mathrm{Cl})$ & \\
\hline \multicolumn{6}{|c|}{ In past 6 months failed to go to the clinic for any reason } \\
\hline Control & $92 / 370(24.9 \%)$ & Reference & $97 / 310(31.3 \%)$ & Reference & \\
\hline Intervention & $73 / 366(20.0 \%)$ & $\begin{array}{l}0.71(0.43-1.1) \\
p \text { value }=0.16\end{array}$ & $64 / 296(21.6 \%)$ & $\begin{array}{l}0.55(0.33-0.90) \\
p \text { value }=0.02\end{array}$ & $\begin{array}{l}0.77(0.46-1.3) \\
p \text { value }=0.34\end{array}$ \\
\hline \multicolumn{6}{|c|}{ In past 6 months, your child/ren needed to go to clinic but failed to go for any reason } \\
\hline Control & $78 / 370(21.1 \%)$ & Reference & $76 / 310(24.5 \%)$ & Reference & \\
\hline Intervention & $65 / 366(17.8 \%)$ & $\begin{array}{l}0.78(0.47-1.3) \\
p \text { value }=0.33\end{array}$ & $46 / 296(15.5 \%)$ & $\begin{array}{l}0.53(0.31-0.91) \\
p \text { value }=0.02\end{array}$ & $\begin{array}{l}0.68(0.38-1.2) \\
p \text { value }=0.18\end{array}$ \\
\hline
\end{tabular}


Table 5 Reported infant feeding practices amongst participating mothers at baseline and follow-up household surveys

\begin{tabular}{|c|c|c|c|c|c|}
\hline & \multicolumn{2}{|c|}{ Baseline household survey } & \multicolumn{2}{|c|}{ Follow-up household survey } & \multirow{2}{*}{$\begin{array}{l}\text { Change-I-C, T1-T2 } \\
\text { OR }(95 \% \mathrm{Cl})\end{array}$} \\
\hline & $N(\%)$ & OR $(95 \% \mathrm{Cl})$ & $N(\%)$ & OR $(95 \% \mathrm{Cl})$ & \\
\hline \multicolumn{6}{|c|}{ Amongst mothers of infants $>6$ weeks: } \\
\hline \multicolumn{6}{|c|}{ Exclusive breastfeeding for first 6 weeks of life } \\
\hline Control & $226 / 312(72.4)$ & Reference & $181 / 278(65.1)$ & Reference & \\
\hline Intervention & 207/317 (65.3) & $0.74(0.49-1.1), p$ value $=0.13$ & 194/253 (76.7) & $1.7(1.1-2.7), p$ value $=0.02$ & $2.3(1.4-4.0), p$ value $=0.001$ \\
\hline \multicolumn{6}{|c|}{ Amongst mothers of infants $<6$ months: } \\
\hline \multicolumn{6}{|c|}{ Ever breastfed infant } \\
\hline Control & 166/199 (83.4) & Reference & 123/151 (81.5) & Reference & Reference \\
\hline Intervention & $164 / 198(82.8)$ & $0.96(0.54-1.7), p$ value $=0.87$ & 128/144 (88.9) & $1.7(0.86-3.5), p$ value $=0.12$ & $1.8(0.78-4.3), p$ value $=0.17$ \\
\hline
\end{tabular}

improved willingness of mothers to disclose their HIV status suggests that relationships and trust between the mother and her $\mathrm{CHW}$ improved in the intervention group. Disclosure of HIV status by mothers to CHWs not only creates additional opportunities for CHWs to provide support and advice to mothers living with HIV and their infants but also requires additional training and skills development.

Reported rates of exclusive breastfeeding for the first 6 weeks of life were higher amongst mothers and infants cared for by CHWs receiving the CQI intervention. This was associated with substantially greater interactions and support by CHWs at home to support optimal early infant feeding practices and improved knowledge about breastfeeding amongst mothers. In particular, there was a substantial increase in the proportion of mothers who received help with breastfeeding from the CHW. It appears that mothers were responsive to this support and, whilst exclusive breastfeeding rates were assessed only at 6 weeks of age, it is plausible that feeding practices improved throughout the first year of life. Improving coverage and duration of exclusive breastfeeding is cited as the most effective intervention to save infant lives and improve child health [24]; our findings highlight the significant role that CHWs may have in support of maternal and infant health. In contrast to facility-based interventions where mothers rely on health workers to deliver a specific service, it appears that mothers supported by CHWs were more likely to take the initiative to improve health outcomes such as through health-seeking behaviour and infant feeding practices.

Although we were unable to demonstrate any change in coverage of facility-based interventions, this is likely because antenatal and postnatal attendance rates were already very high in both control and intervention groups at baseline and there was little scope to improve these. Coverage of HIV interventions was also very high at baseline and did not significantly change during the study period.

Although intervention CHWs received additional training based on the WHO CCM modules [19], it is unlikely that this training alone could account for the observed changes in the intervention arm. Training alone is not likely to change health worker performance [25]. Thus, it is likely that the CQI intervention contributed to the improved outcomes shown in this study which were sustained for more than 1 year following training. Supervision and mentoring of health workers is cited as being essential for improving the quality of service delivery [24-27]. In the same way that WHO recommends training, WHO also considers post-training supervision as integral to IMCI, CCM and the management of children with severe acute malnutrition. However, regular and sustained quality supervision and support for trained health workers is uncommon in health services in both low and middle resource settings $[28,29]$.

CHWs work independently in isolated areas with less formal training than facility-based health workers, and supervision and support is therefore a considerable challenge for health systems. Yet supervision may not only improve performance of CHWs but also raise awareness of their role, legitimise their role in the community and improve $\mathrm{CHW}$ motivation and retention [30, 31]. However, it is unclear which supervision model would be most effective in most settings [28], and there is little robust evidence of effectiveness of supervision models for CHWs. This study implemented a CQI-based mentoring approach amongst CHWs performing their routine work and tasks. CHWs collected specific data elements when visiting families and used these on a regular basis with their supervisor to review performance and outcomes; these were also shared at the joint learning sessions. In the past, CQI approaches have generally been used in health facilities with professional staff; in this study, we adapted such approaches so that CHWs, who had limited literacy and numeracy skills, could still utilise the data-driven method. Our study does not compare whether CQI is more or equally effective than other forms of supervision to improve CHW performance; however, we show that CQI can be successfully adapted for use with this cadre of health worker and performance can be improved. 
A central consideration of any supervision approach in low resource settings must be scalability and sustainability. In our setting, there were relatively large numbers of CHWs compared to supervisors, making the implementation of any supervision framework challenging. In the study, CHWs and supervisors formed small improvement teams that met regularly. Teams also met with other teams to facilitate peer-to-peer learning and problemsolving. All participants commented on the high acceptability and value they attributed to the CQI approach (data not shown). CQI approaches have been successfully implemented in a number of developing country settings, including some community settings [20]. This can be effective and provides a logical supervision and monitoring framework that can link services in facilities with activities in the community including amongst CHWs.

There are important limitations for scaling up the CQI approach used in this proof of concept study. This approach is resource intensive and requires skilled facilitators and tools to support CHWs data collection, and CHWs have to travel to meetings. However, routine supervision meetings do occur and CHWs collect routine data. These processes could be adapted to CQI principles and the CQI approach could provide the strong framework needed to strengthen supervision. However, this would require buy-in and resource allocation from the Department of Health to develop the required systems and will be particularly challenging given differences in $\mathrm{CHW}$ programme administration across districts and provinces. In addition, further evaluation would be required to assess the feasibility and effectiveness of this approach at scale.

\section{Conclusions}

Health systems in southern Africa are commonly underresourced and frequently inaccessible to the poorest and most isolated in the community. CHWs are an important resource for improving the care of mothers and children in communities and for reaching universal coverage of interventions; however, their effectiveness will be constrained unless adequately trained and supported. Failing to invest the additional resources to provide effective supervision, beyond the human resource costs and supplies, may be a false economy.

\section{Abbreviations \\ ANC: Antenatal care; ART: Antiretroviral therapy; CCM: Community case management; CHW: Community health worker; CQI: Continuous quality improvement; HIV: Human immunodeficiency virus; IMCl: Integrated Management of Childhood IIIness; IQR: Interquartile range; KZN: KwaZulu- Natal; OR: Odds ratio; PHC: Primary health care; PMTCT: Prevention of mother-to-child transmission; WHO: World Health Organization}

\section{Acknowledgements}

We dedicate this publication to Dr Jennifer Reddy the principal investigator on this trial and director of the 20000 plus partnership at UKZN who tragically died soon after the work was completed. We would like to thank our talented quality mentors Ellen Ntswe and Khumbusile Sishi for their work with the CCGs.
We wish to acknowledge the input regarding the study design provided by Charles McCulloch, PhD, University of California San Francisco, and statistical analyses provided by Henry Feldman, PhD, Boston Children's Hospital. We would like to thank the KZN Department of Health and Ugu District Management Team for their support. We are especially grateful to the community health workers and mothers who participated in this trial.

\section{Funding}

Funding was provided by Centers for Disease Control and Prevention (U2G/ PS001081) and World Health Organization (2012/288973). Dr. Rollins is an employee of WHO and provided support throughout the research including study design, analysis and preparation of the manuscript. The authors alone are responsible for the views expressed in this publication and do not necessarily reflect the decisions, policy or views of the World Health Organization.

\section{Availability of data and materials}

All data generated or analysed during this study are available on request from the authors.

\section{Authors' contributions}

$\mathrm{CH}, \mathrm{LB}, \mathrm{NR}$ and PB designed the research. MG, NM, SP and LH assisted with the study design. $C H, N M, S P, L H$ and MG oversaw participant recruitment and data collection. $\mathrm{CH}, \mathrm{LB}$ and SP worked on the data analysis. $\mathrm{CH}, \mathrm{LB}$ and NR wrote the manuscript. All authors edited and approved the final manuscript.

\section{Competing interests}

The authors declare that they have no competing interests.

\section{Ethics approval and consent to participate}

Ethical approval was obtained from the Biomedical Ethics Review Committee at the University of KwaZulu Natal (BGC077/11), World Health Organization and the University of California, San Francisco (12-08526). Written informed consent was obtained from all participants.

\section{Disclaimer}

N Rollins is a staff member of the World Health Organization. The authors alone are responsible for the views expressed in this publication and do not necessarily reflect the decisions, policy or views of the World Health Organization.

\section{Publisher's Note}

Springer Nature remains neutral with regard to jurisdictional claims in published maps and institutional affiliations.

\section{Author details}

${ }^{1}$ Centre for Rural Health, University of KwaZulu-Natal, Durban, KwaZulu-Natal, South Africa. ${ }^{2}$ Institute for Collaboration on Health, Intervention and Policy, University of Connecticut, Storrs, CT, United States of America. ${ }^{3}$ Institute for Healthcare Improvement, Cambridge, MA, United States of America.

${ }^{4}$ Department of Maternal and Child Health, Gillings School of Global Public Health, University of North Carolina, Chapel Hill, NC, United States of America. ${ }^{5}$ Department of Maternal, Newborn, Child and Adolescent Health, World Health Organization, Geneva, Switzerland.

Received: 5 January 2017 Accepted: 31 May 2017

Published online: 13 June 2017

\section{References}

1. World Health Organisation. Strengthening the performance of community health workers in primary health care.Technical Report Series 780. World Health Organisation, 1989. ISBN 9241207809.

2. Haines A, Sanders D, Lehmann U, Rowe AK, Lawn JE, Jan S, et al. Achieving child survival goals: potential contribution of community health workers. Lancet. 2007:369(9579):2121-31.

3. Lewin S, Munabi-Babigumira S, Glenton C, Daniels K, Bosch-Capblanch X, van Wyk BE, et al. Lay health workers in primary and community health care for maternal and child health and the management of infectious diseases. Cochrane Database Syst Rev. 2010;3:CD004015.

4. SA National Department of Health. The 2012 national antenatal sentinel HIV and herpes simplex type-2 prevalence survey in South Africa. Pretoria: Department of Health; 2013. 
5. Mayosi BM, Lawn JE, van Niekerk A, Bradshaw D, Abdool Karim SS, Coovadia HM, et al. Health in South Africa: changes and challenges since 2009. Lancet. 2012;380(9858):2029-43.

6. McKerrow NM, Mulaudzi M. South African Health Review 2010. Durban: Health Systems Trust; 2010.

7. Bang AT, Reddy HM, Deshmukh MD, Baitule SB, Bang RA. Neonatal and infant mortality in the ten years (1993 to 2003) of the Gadchiroli field trial: effect of home-based neonatal care. J Perinatol. 2005;25 Suppl 1:S92-107.

8. Manandhar DS, Osrin D, Shrestha BP, Mesko N, Morrison J, Tumbahangphe $\mathrm{KM}$, et al. Effect of a participatory intervention with women's groups on birth outcomes in Nepal: cluster-randomised controlled trial. Lancet. 2004; 364(9438):970-9.

9. Kidane G, Morrow RH. Teaching mothers to provide home treatment of malaria in Tigray, Ethiopia: a randomised trial. Lancet. 2000;356(9229):550-5.

10. Winch PJ, Gilroy KE, Wolfheim C, Starbuck ES, Young MW, Walker LD, et al. Intervention models for the management of children with signs of pneumonia or malaria by community health workers. Health Policy Plan. 2005;20(4):199-212.

11. Darmstadt GL, Choi Y, Arifeen SE, Bari S, Rahman SM, Mannan I, et al. Evaluation of a cluster-randomized controlled trial of a package of community-based maternal and newborn interventions in Mirzapur, Bangladesh. PLoS One. 2010;5(3):e9696.

12. South African National Department of Health. Framework for accelerating community-based maternal, neonatal, child and women's health and nutrition interventions. Available online: http://www.inpracticeafrica.com/ / media/Guidelines/SA_NDOH. Accessed 18 May.

13. de Sousa A, Tiedje KE, Recht J, Bjelic I, Hamer DH. Community case management of childhood illnesses: policy and implementation in Countdown to 2015 countries. Bull World Health Organ. 2012;90(3):183-90

14. Institute for Healthcare Improvement. The breakthrough series: IHI's collaborative model for achieving breakthrough improvement. Boston: Institute for Healthcare Improvement; 2003.

15. George A, Young M, Nefdt R, Basu R, Sylla M, Clarysse G, et al. Community health workers providing government community case management for child survival in sub-Saharan Africa: who are they and what are they expected to do? Am J Trop Med Hyg. 2012;87(5 Suppl):85-91.

16. Webster PD, Sibanyoni M, Malekutu D, Mate KS, Venter WD, Barker PM, et al. Using quality improvement to accelerate highly active antiretroviral treatment coverage in South Africa. BMJ Qual Saf. 2012;21(4):315-24.

17. Youngleson MS, Nkurunziza P, Jennings K, Arendse J, Mate KS, Barker P. Improving a mother to child HIV transmission programme through health system redesign: quality improvement, protocol adjustment and resource addition. PLoS One. 2010;5(11):e13891.

18. O'Neill SM, Hempel S, Lim YW, Danz MS, Foy R, Suttorp MJ, et al. Identifying continuous quality improvement publications: what makes an improvement intervention 'CQI'? BMJ Qual Saf. 2011;20(12):1011-9.

19. World Health Organization. Caring for the sick child in the community: a guide for community health workers World Health Organization; 2011 Contract No.: 4/05/16. ISBN: 9789241548045 . Available at http://www.who. int/maternal_child_adolescent/documents/newborn-child-community-care/ en/

20. Horwood CM, Youngleson MS, Moses E, Stern AF, Barker PM. Using adapted quality-improvement approaches to strengthen community-based health systems and improve care in high HIV-burden sub-Saharan African countries. AIDS (London, England). 2015:29 Suppl 2:S155-64.

21. Littell RC FR, Spector PC. SAS System for Linear Models: third edition. SAS Institute: 1991.

22. Liang KY, Zeger SL. Longitudinal data analysis using generalized linear models. Biometrika. 1986;73:13-22.

23. Hardin JW, Hilbe JM. Generalized estimating equations. Chapman \& Hall/ CRC: Boca Raton; 2003.

24. Victora CG, Bahl R, Barros AJ, Franca GV, Horton S, Krasevec J, et al. Breastfeeding in the 21 st century: epidemiology, mechanisms, and lifelong effect. Lancet. 2016;387(10017):475-90.

25. Rowe AK, de Savigny D, Lanata CF, Victora CG. How can we achieve and maintain high-quality performance of health workers in low-resource settings? Lancet. 2005;366(9490):1026-35.

26. Ashworth A, Chopra M, McCoy D, Sanders D, Jackson D, Karaolis N, et al. WHO guidelines for management of severe malnutrition in rural South African hospitals: effect on case fatality and the influence of operational factors. Lancet. 2004;363(9415):1110-5.
27. Steinhardt LC, Onikpo F, Kouame J, Piercefield E, Lama M, Deming MS, et al. Predictors of health worker performance after Integrated Management of Childhood Illness training in Benin: a cohort study. BMC Health Serv Res. 2015;15:276

28. Hill Z, Dumbaugh M, Benton L, Kallander K, Strachan D, ten Asbroek A, et al. Supervising community health workers in low-income countries-a review of impact and implementation issues. Glob Health Action. 2014;7:24085.

29. Goga AE, Muhe LM. Global challenges with scale-up of the integrated management of childhood illness strategy: results of a multi-country survey. BMC Public Health. 2011;11:503.

30. Roberton T, Applegate J, Lefevre AE, Mosha I, Cooper CM, Silverman M, et al. Initial experiences and innovations in supervising community health workers for maternal, newborn, and child health in Morogoro region, Tanzania. Hum Resour Health. 2015;13:19.

31. Strachan DL, Kallander K, ten Asbroek AH, Kirkwood B, Meek SR, Benton L, et al. Interventions to improve motivation and retention of community health workers delivering integrated community case management (iCCM): stakeholder perceptions and priorities. Am J Trop Med Hyg. 2012;87(5 Suppl):111-9.

\section{Submit your next manuscript to BioMed Central and we will help you at every step:}

- We accept pre-submission inquiries

- Our selector tool helps you to find the most relevant journal

- We provide round the clock customer support

- Convenient online submission

- Thorough peer review

- Inclusion in PubMed and all major indexing services

- Maximum visibility for your research

Submit your manuscript at www.biomedcentral.com/submit
) Biomed Central 